\title{
Hands-On Design and Construction of Light Frame Buildings in the Light Frame Building Systems Course
}

\author{
Kris J. Dick and Qiang Zhang \\ Department of Biosystems Engineering, University of Manitoba, Winnipeg, MB R3T 5V6 \\ Corresponding Author E-mail Address: kjdick@ad.umanitoba.ca
}

Abstract - A specialization in Sustainable Building Systems is offered in Biosystems Engineering. We have observed that many of our students have little practical knowledge of, nor experience with building construction. Since the introduction of this course a design project integrated with hands-on labs has been included. The importance of hands-on learning is reinforced constructing a small-scale building. Students use the knowledge from this class combined with skills learned in other courses in their program to design and build a prototype. Linking design to construction gives the students a unique opportunity to gain insight into the relationship between theory and practice, while also learning from their "mistakes". This paper summarizes three years of experience teaching this course.

Keywords: light frame building, hands-on learning, prototyping, engineering education.

\section{INTRODUCTION}

A course in light frame building design has been a part of Biosystems Engineering at the University of Manitoba for many years. For the purposes of this course light frame buildings are defined as those whose dead load is substantially less than the live loads they support. Post frame structures, fabric-covered building and wood frame construction are included in this definition. Recently the concepts of light frame building structural design were combined with building envelope and HVAC design to provide students with a sense of how a building functions as a system. The objective of this course is to provide students with an understanding of building system design from foundations to roofs. Through the course students are expected to gain experience in designing structures and built-environment of light-frame buildings. It has been our experience that students often do not appreciate the importance of the link between structural systems and building envelope performance. In addition to fundamental theory, students work on an integrated design and construction project that provides hands-on experience with a component of a building system. The course is open to students from Biosystems and Civil Engineering.

\section{PROJECT DESIGN AND CONSTRUCTION PROCESS}

Each year the design project is the same for all groups, however each team is expected to develop their own unique approach. Students form design teams of 3-5 people at the beginning of the term. In the first two to three labs the teams develop their conceptual designs. The groups present their designs to the entire class for brainstorming, discussion and critique.

Once each team has decided on their approach they focus on analysis and design refinement. All students are required to maintain a journal to track their design process. As each design team is required to submit a final report, 
the importance of the journal is reinforced as a source of documentation for report preparation. A set of construction drawings forms a mandatory component of the report.

Each team must prepare a list of materials for constructing their pilot-scale buildings (or building components). This list is submitted to the instructors and the Biosystems Engineering technicians. They are responsible for "ordering" their materials. This means they must provide the appropriate notice for material purchase. If a design team does not have their request in on time they do not have the material for the lab. This is done to reinforce the importance of project planning and work flow.

At the end of the term each group presents their design combined with a demonstration of their project. Two of the projects summarized in this paper were evaluated for thermal performance. These data were collected and compared to theoretical calculations.

All materials for these projects have either been purchased by the Biosystems Engineering department or supported through fund raising.

\section{PROJECT EXAMPLES}

Three projects have been done since the course was introduced. These include a wood frame building, the back wall of a solar energy greenhouse and a solar wall system.

\subsection{Wood Frame Building}

During the first offering of the course students worked in teams to design various components of a wood-frame structure (Fig.1). This building was to be used in conjunction with a greenhouse as a growth chamber to start bedding plants. The design had to include not only structural aspects but also address higher moisture content within. The building size is 2.4 $\mathrm{m}$ wide $\mathrm{x} 4.8 \mathrm{~m}$ long with $2.4 \mathrm{~m}$ high walls $(8 \mathrm{x}$ $16 \times 8$ feet). Construction is $2 \times 6$ stud walls at
$400 \mathrm{~mm}$ (16") on centre with $12 \mathrm{~mm}(1 / 2 ")$ plywood sheathing on both sides. Insulation is fiberglass batt with 6 mil vapour barrier. The students designed the dimensional lumber trusses.

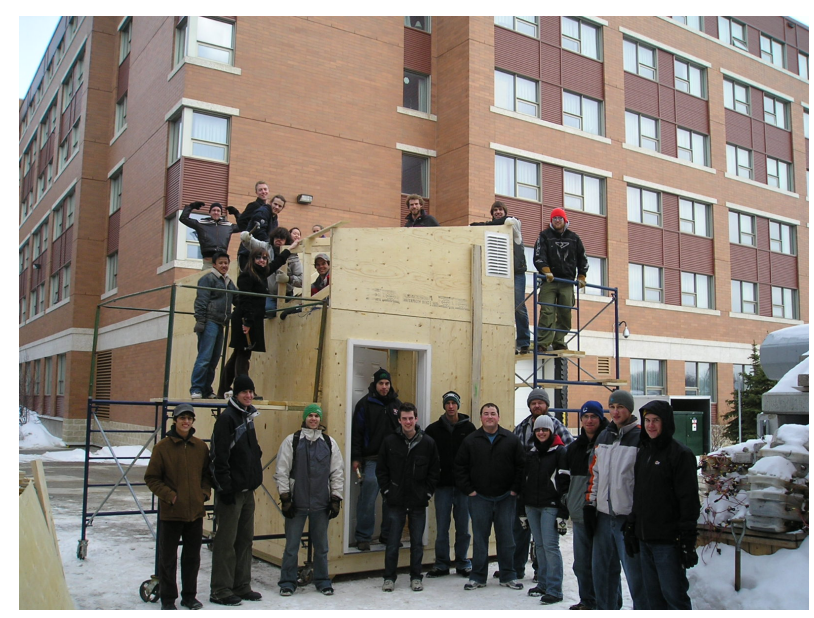

Fig.1. A small scale wood building constructed by students in the class

To gain some insight as to how the building performed T-type thermocouples were installed in all walls, at corners, the underside of the framed floor and in the attic space. Data from the thermocouples were used to compare theoretical to actual conditions within the wall cavity.

The students gained experience with building what many thought would be a "simple box". Installation of a door, roof trusses, roof covering and keeping the whole structure square was more of a challenge then many thought. While only anecdotal, all students indicated that they had learned a lot by seeing how all of the components came together.

\subsection{Solar Energy Greenhouse}

The next project presented was the design of the rear wall of a solar energy greenhouse. This system was comprised of steel frames spaced at $1.5 \mathrm{~m}(5 \mathrm{ft})$ on centre that form the cross section of the structure [1]. The backwall of greenhouse was used to provide insulation and a heat sink that absorbs solar 
energy for release into the growing area after sundown. A total of six design teams were formed and each presented an approach for the back wall. Each of these teams defended their design in presentations to the class. The merits of the various designs were discussed and two were selected for construction. Figure 2 shows the class in front of the solar backwall systems. Feedback from the students indicated that they gained much from the experience. As with most designs certain aspects were modified along the way that provided the opportunity for the class to discuss options and then move forward.

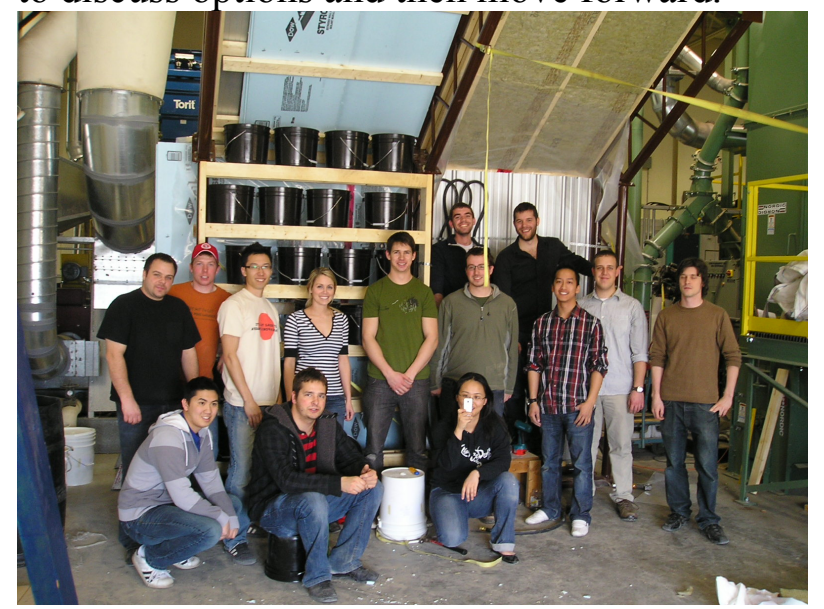

Fig. 2. Greenhouse solar backwall designed and constructed by the class

\subsection{Solar Wall Panel}

The most recent project was the design and construction of a solar wall panel. Three teams worked on the design of a $1.2 \mathrm{~m}$ by $2.4 \mathrm{~m}$ $(4 \mathrm{ft} \times 8 \mathrm{ft})$ wall panel that could preheat incoming air into a building. The systems constructed were:

- Metal tubing behind a plexiglass cover

- Baffles behind a metal cover

- Plaster on insulation with plexiglass cover

Each panel was tested for heat gain and air movement. Thermocouples were placed inside the collector and outside for ambient air temperature. A hot wire anemometer was used to determine the airflow out of the collector unit. The relationship between heat produced and airflow was determined for each panel. Based on the test results students determined how many of their panels would be needed to heat a warehouse type structure.

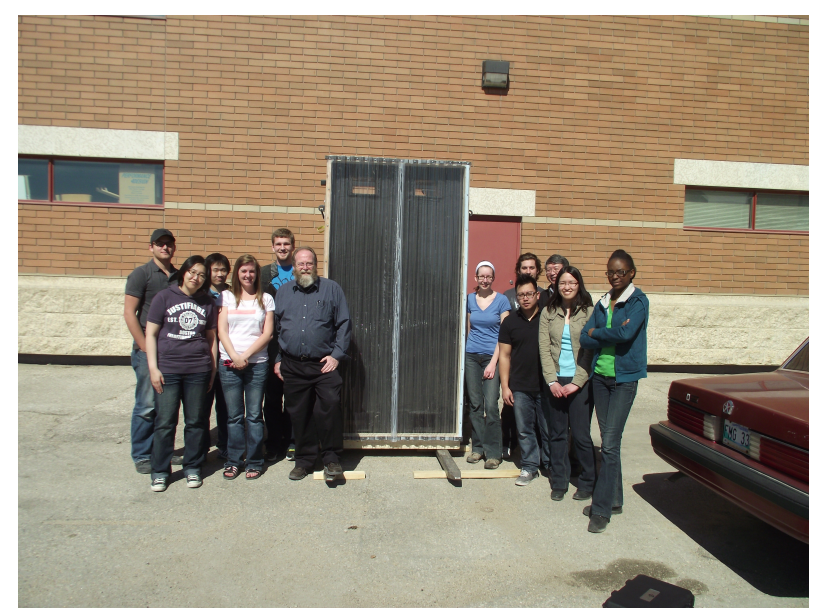

Fig. 3. A solar wall panel designed and constructed by a team

\section{SUMMARY}

Regardless of the project the authors believe there are a number of benefits for both the students and course instructors. During the hands-on labs the pedagogical model is more that of an apprenticeship style. The instructors can connect with the students on a more informal level and work with them as they evaluate design options. The students have always seen the construction aspect of the course as a positive experience. For many of them this the first time they have used various tools and had to think about how to assemble various building components. Essentially putting their thoughts into practice builds confidence and team skills. Each time the course is offered we ask the students to provide feedback on the process and what they learned. The predominant comment that comes back is they really appreciate learn by doing. They are often surprised at how something that seemed quite simple conceptually required a lot of thought and expertise to accomplish. 


\section{CONCLUSION}

This paper has briefly summarized hands-on lab experience for a design course in Biosystems Engineering at the University of Manitoba. Creating a formal linkage between design and construction provides students with valuable experience with the application of engineering principals. Through the evaluation of their designs students are able to compare theory with practice that will provide them with a "feel" for what they have designed

\section{Acknowledgements}

The authors would like to thank the Department of Biosystems Engineering for its support of the course BIOE4412, the Biosystems Department technicians and the Faculty of Agriculture and Food Sciences for financial support.

\section{References:}

[1] Yusim, M. and Dick, K.J. 2011. Preliminary Results of Solar Energy Greenhouse Research at the University of Manitoba's Alternative Village. CSBE 2011 Annual Conference, Winnipeg, Manitoba, Canada 